\title{
RHEUMATIC DISEASE IN THE MIDDLE EAST
}

\section{G. D. KERSLEY}

A war will sometimes produce the opportunity for obtaining figures, not normally available, of the incidence of a disease and its reactions under varying conditions of climate and strain.

Facts that may have any bearing on the aetiology or classification of the rheumatic diseases are badly needed, and with this end in view an effort was made to analyse figures of morbidity among our troops in the Middle East. In order to obtain information on the number of different types of rheumatism occurring in a healthy population of young adults, under different seasonal and climatic conditions, the reports of all hospitals were carefully analysed over the period of some twelve months. In assessing the effect of climate, however, such figures have to be treated with caution owing to the movement of troops from one country to another within the Command, and in consideration of the fact that in some countries, such as Palestine, there were included among the admission records a number of local enlistments, whose psychology has to be borne in mind in assessing the exactitude of diagnosis wherever this rested on clinical history rather than on unmistakable physical signs.

\section{Incidence}

For the purpose of this investigation, under the heading of rheumatic diseases were included all cases of arthritis, fibrositis, and sciatica admitted to any hospital in Egypt, Palestine, Syria, Tripolitania, or Malta for either investigation or treatment. In the period under review there were 1,288 cases in this group, which comprised 2.5 per cent. of all medical admissions. In Palestine and Syria, where the winter and early spring is in many places very wet and cold, the incidence was a little higher $(2 \cdot 9$ per cent.), and in Egypt, with its temperate winter, hot dry early summer, and humid autumn, the incidence was 2.2 per cent. The highest seasonal incidence-namely, 5.1 per cent.-was in the first quarter of the year, dropping to 3.2 per cent. between April and June, to 1.9 per cent. between July and September, and rising a little to 2.6 per cent. in the last quarter of the year.

\section{Types of Disease}

The sub-division of rheumatic cases into clinical syndromes on the basis of the reports was possible in only 775 of the cases. Of these, 33 per cent. could be classed as muscular fibrositis, 32 per cent. as acute joint conditions, 21 per cent. as chronic arthritis, and 14 per cent. as sciatic pain. Of these syndromes, the differential diagnosis and aetiology of the acute joint conditions in particular presented interesting problems, raising the question both of the inter-relationship of acute rheumatic fever in adults to other forms of rheumatism, and also of the virus factor in aetiology. Bearing on the first problem, Ferguson (1943), in a review of 243 cases of acute arthritis of the same age group in the Canadian Army, found that in 58 per cent. symptoms began within 12 weeks of an acute streptococcal infection, and that in 71 per cent. of these, symptoms occurred within 2 weeks and in 95 per cent. within 4 weeks of its onset. Twenty per cent. gave a past history of rheumatic fever, 27 per cent. eventually developed cardiac lesions thought to be rheumatic, and 6 per cent. progressed to a chronic rheumatoid syndrome. He stated that 71 per cent. re-acted favourably to salicylates, and that many of the remainder had never received full doses of this drug. His findings, therefore, bear out the suggestion that one large group of cases are suffering from the adult form of acute rheumatic fever.

In addition to this acute form of adult rheumatism, there exists a subacute, more insidious type, corresponding to the subacute rheumatism of childhood. These cases again often give a past history of rheumatic fever and sometimes show signs of a valvular lesion. They complain of aching in certain joints, especially the wrists and elbows, symptoms coming on most frequently two weeks after a nasal or tonsillar infection. There is often a little transient swelling and there may be signs of re-activation of an old carditis. The sedimentation rate is normal or only slightly raised, the course is chronic, and the results of treatment, including that obtained by the exhibition of salicylates, are far from dramatic. Of 13 cases followed up for a period of 5 years, one developed a polyarthritis, 4 still had periodic attacks of arthralgia, 2 had a slightly swollen joint at the time of review, and 6 considered themselves completely cured (Kersley, 1939). Out of this small group of "subacute rheumatic infections," at first clinically indistinguishable, emerges a case of true arthritis, others that could justifiably be diagnosed as peri-articular fibrositis, yet some at least were undoubtedly of the same aetiology as juvenile rheumatism.

Other types of arthritis that must be considered in differential diagnosis, in addition to those due to well-defined specific infections such as gonorrhoea 
and to juvenile gout, are acute osteo-arthritis; a multiple arthritis of the small joints with absence of constitutional debility or trophic changes in the skin, and with a normal or only slightly raised sedimentation rate; palindromic rheumatism, rare in this country, but described by Hench and Rosenberg (1941) as a syndrome of transient attacks of pain, swelling and redness of one or more joints in adults of either sex, recurrent over a period of many years, and accompanied by no constitutional, blood, or $\mathrm{x}$-ray changes; and the arthritis accompanying nonspecific urethritis. This latter condition brings us to the second question-that of a virus factor in aetiology.

\section{The Infective Factor}

Van Rooyen believes that those cases with acute arthritis following non-specific urethritis and usually associated with some iritis or conjunctivitis, a syndrome not uncommon in the Middle East, were caused by infection with the Waelsch virus, also responsible for swimming-bath conjunctivitis, and inclusion urethritis and cervicitis. For these latter conditions the incubation period is stated to be 6-10 days. More work, however, is required, including the examination of urethral scrapings and the carrying out of Frei antigen tests, to prove or disprove this hypothesis. Corroborative evidence for this theory was afforded by Eagles et al. (1937), who described the presence of inclusion bodies in the pericardium and joints of children dying from rheumatic fever. When, however, the present evidence for a virus is weighed against that for a streptococcal origin it carries little weight unless the effect of symbiosis is remembered.

The work of Rosenow (1923), who showed that two-thirds of a series of rheumatic subjects had their rheumatic state re-activated by an epidemic of haemolytic streptococcal infection, but were not affected in this way by infections with other types of organism, of Coburn (1931), who demonstrated that exacerbations of rheumatism in children could be stopped by their transference to a climate which caused the disappearance of streptococci from the flora of the nasopharynx, of Collis (1939) who carried out cultural examinations post mortem on tonsillar tissue, and of Green (1939), who obtained a similar result from hearts from rheumatic fever cases, leaves little doubt that the streptococcus plays some part in the causation of rheumatic fever.

Similarly, the blood and joint culture work of Cecil (1929) and Gray (1932), though disputed by some, when backed by the agglutination and skin sensitivity tests of Keefer (1933), produce strong evidence that there is some similar factor in many cases of rheumatoid arthritis. The evidence in all these cases, however, is not completely convincing in itself: two other factors require considerationthat of allergy or sensitization, and that a virus may be necessary in symbiosis with the causative bacterium in order to produce the clinical syndrome of rheumatism. The question of tissue sensitization is too large a subject to embark on here, but the incubation period between evidence of infection and rheumatic symptoms, the results of skin sensitization tests, and the experimental work on immune body response in rheumatic subjects all suggest that allergy will be found to play a part in the jig-saw puzzle.

The most recent experimental work throwing light on the symbiosis theory is that of Gordon (1939), who produced arthritis in rabbits by the combined intravenous injection of a streptococcus and M4 virus-neither producing the condition by themselves when used in the same dosage and only the virus being recoverable from the tissues. May not the need for a similar symbiosis between a virus and certain bacteria be responsible for the difficulties in interpreting results of many experiments based on the conception that rheumatism is due to a specific bacterium, for the difficulty in obtaining a specific bacterium from the tissues in 100 per cent. of cases in one particular type of rheumatic disease, for the results of the transmission experiments recorded by Copeman (1944), for the way in which cases of nonspecific urethritis develop arthritis, and for the relapse which frequently occurs (Kersley 1942) when patients suffering from a non-specific type of rheumatism become infected with gonorrhoea?

Much more research combined with clinical observation is necessary before we can interpret all the facts; but the conception of the triad, $(a)$ bacterial infection, probably non-specific; (b) virus in symbiosis; and $(c)$ tissue sensitization, opens up a huge field for future investigation.

\section{Summary and Conclusions}

Some figures concerning the seasonal incidence of rheumatic disease among our Forces in different countries in the Middle East have been given.

Evidence bearing on theories of a virus or virus and bacterial causation of rheumatism are discussed, together with views on the relationship of the rheumatic syndromes seen among young adults to those found in children.

\section{REFERENCES}

Cecil, R. L., Nicholls, E. E., and Stainsbury, W. J. (1929). J. Exper. Med., 50, 617.

Coburn, A. F. (1931). The Factor of Infection in the Rheumatic State, Baltimore.

Copeman, W. S. C. (1944). Ann. Rheum. Dis., 4, 37.

Collis, W. R. F. (1939). Lancet, 2, 817.

Eagles, G. H. et al. (1937). Lancet, 2, 421.

Ferguson, G. C. (1943). Canad. Med. Ass. J., 49, 492

Gordon, M. H. (1939). Ann. Rheum. Dis., 1, 5.

Green, C. A. (1939). J. Roy. Nav. Med. Serv., 25, 218

Gray, J. W. et al. (1932). Texas State J. of Med., 28, 203.

Hench, P. S., and Rosenberg, E. F. (1941). J. Amer. Med. Ass., 117, 1560 .

Keefer, C. S., et al. (1933). J. Clin. Invest., 12, 267.

Kersley, G. D. (1942). Proc. Roy. Soc. Med., 35, 653.

Rosenow). J. Roy. Inst. Pub. Hlth., 2, 101.

. $26,23$. . London. 